\title{
PELAKSANAAN FUNGSI MANAJEMEN (PLANNING, ORGANIZING, ACTUALLING, CONTROLLING) PADA MANAJEMEN MASJID AL-AKBAR SURABAYA(1)
}

\author{
Faiz Alan Fahmi \\ Mahasiswa Program Studi S1 Ekonomi Islam-Fakultas Ekonomi dan Bisnis-Universitas Airlangga \\ Email : faiz-a-f-11@feb.unair.ac.id
}

\author{
A.Syifa'ul Qulub \\ Departemen Ekonomi Syariah-Fakultas Ekonomi dan Bisnis-Universitas Airlangga \\ Syfa-q@feb.unair.ac.id
}

\begin{abstract}
:
The purpose of this research is to knowing the role of asset management in an attempt to managing financial independence and optimizing economic activities in Masjid Al-Akbar Surabaya. This research uses qualitative method with descriptive case study, while collecting the data uses purposive technique to specify the informan. The data used in this research is obtained by semi-structured interview, observation, and documentation. This research also uses triangulation techinique in checking the data validation. Triangulation is an examination technique which enables to use one or two another sources for validation or verification. The result of this research showing that asset management of Masjid Al-Akbar has been operated in accordance with asset management's functions which is including planning, organizing, implementing, and controling which then result in financial indepedence of Masjid Al-Akbar Surabaya.
\end{abstract}

Keywords: Asset Management, Mosque Management, Financial Independence

\section{PENDAHULUAN}

\section{Latar Belakang}

Masjid merupakan tempat orang berkumpul dan melakukan shalat secara berjamaah dengan tujuan sebenernya adalah meningkatkan solidaritas dan silaturahmi di antara kaum Muslim. Secara teoritis-konseptual, masjid adalah kebudayaan islam, dari tempat inilah syiar islam yang meliputi aspek duniawi dan ukhrawi, material-spritual dimulai. Masjid menempati posisi sangat istimewa dalam doktrin dan kultur Islam, sebab ia menjadi pilar spiritual yang menyangga kehidupan duniawi umat. Masjid memiliki peranan strategis untuk kemajuan peradaban umat muslim, sejarah telah membuktikan multi fungsi peranan masjid tersebut (Gazalba, 1975:55).

Sebagai kota terbesar kedua setelah ibukota Jakarta, Surabaya memiliki potensi keagamaan yang cukup besar. Kota yang berpenduduk 2.761.840 jiwa, dengan keragaman pemeluk agama: Islam 2.237 .090 (81\%), Kristen 256.022 (9,27\%), Katholik 154.663 (5,06\%), Hindu 55.236 $(2,02 \%)$ dan Budha atau Konghucu 48.332 $(1,75 \%)$. Selaras dengan jumlah pemeluk agama, Surabaya memiliki rumah ibadah sebagai sarana ibadah dan pengembangan agama; Masjid 1.252

(1) Jurnal ini merupakan bagian dari Faiz Alan Fahmi, NIM: 041114054 , yang diuji pada tanggal 9 Februari 2017 
Fahmi, et al/Jurnal Ekonomi Syariah Teori dan Terapan Vol. 4 No. 12 Desember 2017: 968-976; PELAKSANAAN FUNGSI MANAJEMEN (PLANNING, ORGANIZING, ACTUALLING, CONTROLLING) PADA MANAJEMEN MASJID AL-AKBAR SURABAYA

buah, Gereja Kristen Protestan 396 Buah, Gereja Kristen Katolik 75 buah , Pura delapan buah, Vihara 12 buah, dan Klenteng lima buah (Kemenag, 2013).

Dari data di atas dapat disimpulkan bahwasannya Surabaya memiliki jumlah rumah ibadah sebagai potensi pengembangan agama, sehingga dalam praktiknya dapat memberdayakan setiap pemeluknya.

Menurut Al-Faruq (2010:234), masjid di zaman sekarang tidak sedikit yang membentuk berbagai unit usaha, sehingga dengan unit usaha yang ada mampu menopang berbagai macam kegiatan dalam rangka memakmurkan masjid. Aktivitas ekonomi yang dipilih biasanya terdapat dua pilihan yaitu di bidang jasa dan perdagangan, meskipun tidak menutup kemungkinan adanya usaha ekonomi masjid di bidang produksi (Rivai dan Buchari, 2009:68).

Dalam kegiatan ekonomi inilah, diperlukan sebuah mekanisme teknik yang lebih dikenal dengan manajemen, yang tidak lain bertujuan untuk menciptakan dan mewujudkan efektivitas dan efisiensi dalam memberdayakan dan memakmurkan masjid yang dilakukan secara bersama baik oleh masyarakat maupun para pengurus masjid secara khusus. Intinya, dengan manajemen yang handal, upaya untuk menyelenggarakan kegiatan ekonomi akan menemukan bentuknya yang paling sempurna dan ini akan menjamin kesejahteraan jamaah umat Islam, khususnya yang berada di sekitar masjid (Rivai dan Buchari, 2009:68).

Aset adalah suatu kekayaan yang dimiliki oleh suatu pihak yang berwujud maupun tidak berwujud yang memiliki nilai ekonomis, komersial, dan nilai tukar untuk membantu tercapainya tujuan (Baridwan, 2004:271).

Seperti halnya Masjid Al-Akbar Surabaya. Masjid Al Akbar Surabaya (MAS) menjadi salah satu potret sosok masjid yang menjadi pilar aktivitas sosial. Masjid itu menjadi masjid terbesar kedua di Indonesia, yang mendampingi sekaligus melengkapi masjid yang dimiliki Indonesia sebelumnya. Masjid Al Akbar berdiri di atas lahan seluas 11.2 hektar dan mulai dibangun pada 4 Agustus 1995-ditandai peletakan batu pertama oleh wakil presiden Try Sutrisno. Pada 20 November 2000 masjid itu diresmikan Presiden $\mathrm{KH}$ Abdurrahman Wahid dan mampu menampung 30.000 jama'ah. Masjid terbesar di Jawa Timur ini sedang bergelimang aset, tetap maupun tidak. Dibutuhkan manajemen yang baik dalam pengelolaannya.(Fadillah, 2011:58)

Alasan peneliti mengambil Yayasan Masjid Al-Akbar sebagai studi kasus dalam penelitian ini karena masjid ini adalah masjid terbesar kedua di Indonesia setelah masjid Istiqlal di Jakarta dan sudah memiliki beberapa kegiatan ekonomi mulai dari perdagangan dan jasa dan bisa menjadi contoh untuk masjid-masjid lainnya. 
Fahmi, et al/Jurnal Ekonomi Syariah Teori dan Terapan Vol. 4 No. 12 Desember 2017: 968-976; PELAKSANAAN FUNGSI MANAJEMEN (PLANNING, ORGANIZING, ACTUALLING, CONTROLLING) PADA MANAJEMEN MASJID AL-AKBAR SURABAYA

Berdasarkan uraian latar belakang di atas maka penulis mengambil rumusan masalah,"Bagaimana penerapan Manajemen Aset Masjid Al-Akbar Surabaya dalam membangun kemandirian ekonomi Masjid tersebut?"

Berdasarkan latar belakang dan rumusan masalah yang dipaparkan dan dijelaskan di atas, maka tujuan dari penelitian ini adalah untuk mengetahui peran manajemen aset masjid pada Yayasan Masjid Al-Akbar Surabaya dalam bentuk perencanaan, pengorganisasian, pelaksanaan, dan pengendalian untuk membangun kemandirian masjid.

\section{TINJAUAN PUSTAKA}

Menurut Thaha (2006:11) dalam bukunya menjelaskan bahwa masjid berasal dari bahasa arab sajada yang berarti tempat sujud atau tempat menyembah Allah SWT. Masjid bagi kaum muslimin, dan masjid tidak bisa dilepaskan dari masalah shalat.

Salah satu unsur penting dalam pembangunan berstruktur masyarakat madani dalam Islam adalah masjid. Nabi Muhammad merintis terbentuknya satu model kehidupan masyarakat madani (civil society) dengan masjid sebagai pusat kegiatannya. Penyelenggaraan berbagai kegiatan yang dipusatkan di masjid pada saat itu karena disadari bahwa masjid memang merupakan pusat pembinaan masyarakat (Syahidin, 2003:75).
Daft (2002:2) mengartikan manajemen sebagai pencapaian sasaran-sasaran organisasi dengan cara yang efektif dan efisien melalui perencanaan, pengorganisasian, kepemimpinan, dan pengendalian sumberdaya organisasi. Ada dua ide penting dalam definisi ini, pertama kaitannya dengan fungsi manajemen dan pencapaian sasaran-sasaran organisasi dengan cara yang efektif dan efisien.

Menurut Djarwanto (2001:15) aset merupakan bentuk dari penanaman modal perusahaan, bentuk-bentuknya dapat berupa harta kekayaan atau hak atas kekayaan atau jasa yang dimiliki perusahaan yang bersangkutan. Menurut Mamduh Hanafi (2003:24) aset adalah sumber daya yang dikuasai oleh perusahaan sebagai akibat dari peristiwa masa lalu dan darinya manfaat ekonomi di masa depan diharapkan akan diraih oleh perusahaan.

Pengelompokan aset menurut Sukmalana (2007:39) dibagi menjadi tiga, yaitu:

1. Aset Lancar

Aset lancar adalah aset yang dapat dicairkan dengan segera untuk dijadikan uang tunai, dijual atau digunakan pada periode berikutnya. Biasanya periodenya satu tahun atau kurang.

2. Aset Tetap

Aset tetap adalah kekayaan perusahaan yang pemakaiannya dalam waktu lama (lebih dari satu periode akuntansi). Aset 
Fahmi, et al/Jurnal Ekonomi Syariah Teori dan Terapan Vol. 4 No. 12 Desember 2017: 968-976; PELAKSANAAN FUNGSI MANAJEMEN (PLANNING, ORGANIZING, ACTUALLING, CONTROLLING) PADA MANAJEMEN MASJID AL-AKBAR SURABAYA

tersebut digunakan dalam kegiatan normal perusahaan serta mempunyai nilai material yang relatif besar, misalnya: tanah, bangunan, mesin, kendaraan.

3. Aset Tetap tidak berwujud Aset tetap tidak berwujud (intangible fixed assets) adalah hak istimewa yang dimiliki perusahaan dan mempunyai nilai, namun tidak mempunyai bentuk fisik.

\section{Manajemen Aset}

Pengelolaan aset menurut Siregar (2004:517) adalah merupakan salah satu profesi atau keahlian yang belum sepenuhnya berkembang dan popular di lingkungan pemerintahan maupun di satuan kerja atau instansi. Sedangkan menurut Sugiama (2013:15) berdasarkan pada pengelolaan aset fisik, secara definitif manajemen aset adalah ilmu dan seni untuk memandu pengelolaan kekayaan yang mencakup proses merencanakan kebutuhan aset, mendapatkan, menginventarisasi, melakukan legal audit, menilai, mengoperasikan, memelihara, membaharukan atau menghapuskan hingga mengalihkan aset secara efekif dan efisien.

Manajemen aset diperlukan karena kita tidak bisa mengetahui apa yang akan terjadi besok. Oleh sebab itu kita harus berjaga-jaga jika kita tertimpa musibah, sudah ada cadangan aset yang telah kita persiapkan. Dalam Al-Qur'an telah dijelaskan dalam Surat Luqman ayat 34 dan Surat Al-Hasyr ayat 18 yang berbunyi :

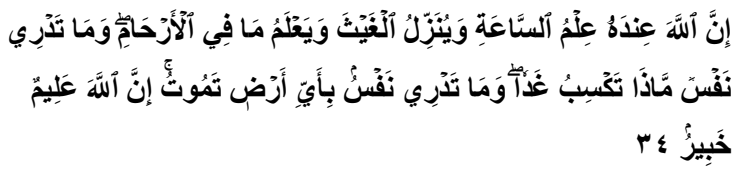

Artinya: "Sesungguhnya Allah, hanya pada sisi-Nya sajalah pengetahuan tentang hari Kiamat; dan Dia-lah yang menurunkan hujan, dan mengetahui apa yang ada dalam rahim. dan tiada seorangpun yang dapat mengetahui (dengan pasti) apa yang akan diusahakannya besok. dan tiada seorangpun yang dapat mengetahui di bumi mana Dia akan mati. Sesungguhnya Allah Maha mengetahui lagi Maha Mengenal." (QS. Luqman: 34)

Penekanan dalam ayat tersebut adalah pentingnya memikirkan apa yang terjadi di masa depan. Karena tidak seorangpun yang bisa memastikan apa yang akan terjadi di kemudian hari.

\section{Kemandirian Kevangan Masjid}

Halim (2007) berpendapat bahwa kemandirian kevangan daerah menunjukkan kemampuan pemerintah daerah dalam membiayai sendiri kegiatan pemerintahan, pembangunan dan pelayanan kepada masyarakat yang telah membayar pajak dan retribusi sebagai sumber pendapatan yang diperlukan daerah. Kemandirian keuangan daerah ditujukan oleh seberapa besar kecilnya pendapatan asli daerah (PAD) dibandingkan dengan pendapatan daerah yang berasal dari sumber lain, misalnya bantuan pemerintah pusat ataupun dari pinjaman. 
Fahmi, et al/Jurnal Ekonomi Syariah Teori dan Terapan Vol. 4 No. 12 Desember 2017: 968-976; PELAKSANAAN FUNGSI MANAJEMEN (PLANNING, ORGANIZING, ACTUALLING, CONTROLLING) PADA MANAJEMEN MASJID AL-AKBAR SURABAYA

Allah SWT bahkan sudah memerintahkan kita untuk bekerja karena Allah SWT menjanjikan akan mendapatkan balasan yang setimpal untuk mereka yang bekerja, seperti yang sudah disebutkan dalam AlQur'an Surat At-Taubah ayat 105, yang berbunyi:

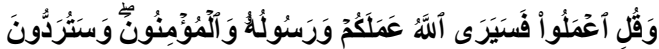

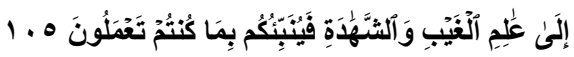

Artinya: "dan Katakanlah: "Bekerjalah kamu, Maka Allah dan Rasul-Nya serta orangorang mukmin akan melihat pekerjaanmu itu, dan kamu akan dikembalikan kepada (Allah) yang mengetahui akan yang ghaib dan yang nyata, lalu diberitakan-Nya kepada kamu apa yang telah kamu kerjakan." (QS. At-Taubah: 105)

Rasio kemandirian menggambarkan tingkat ketergantungan daerah terhadap sumber dana eksternal. Semakin tinggi rasio kemandirian berarti tingkat ketergantungan daerah terhadap bantuan pemerintah pusat dan provinsi semakin rendah, demikian pula sebaliknya.

Rasio kemandirian keuangan Masjid menunjukkan kemampuan Masjid dalam membiayai sendiri aktivitas Masjid dan pembangunan. Rasio ini juga menggambarkan ketergantungan Masjid terhadap sumber dana eksternal. Semakin tinggi rasio kemandirian, maka tingkat ketergantungan Masjid terhadap dana eksternal semakin rendah, begitu juga sebaliknya.

\section{METODE PENELITIAN}

\section{Pendekatan Penelitian}

Penelitian ini menggunakan metode kualitatif. Metode penelitian kualitatif merupakan penelitian naturalistik karena penelitiannya dilakukan pada kondisi yang alamiah (natural setting).

Penelitian ini menggunakan pendekatan studi kasus. Menurut Yin (2014:1), Secara umum studi kasus merupakan strategi yang lebih cocok bila pokok pertanyaan suatu penelitian berkenaan dengan how atau why, bila fokus penelitiannya terletak pada fenomena kontemporer (masa kini) di dalam konteks kehidupan nyata.

\section{Ruang Lingkup Penelitian}

Ruang lingkup penelitian terkait dengan rumusan masalah dalam penelitian ini. Rumusan masalah dalam penelitian ini adalah mengenai bagaimana penerapan manajemen keuangan dan aset pada masjid Al-Akbar Surabaya untuk mengoptimalkan keuangan masjid tersebut. Rumusan masalah tersebut menjadi acuan peneliti dalam menentukan ruang lingkup penelitian.

\section{Jenis dan Sumber Data}

Data yang dikumpulkan dalam penelitian kualitatif ini dibagi menjadi dua yaitu data primer dan data sekunder atau penunjang.

Data primer merupakan sumber-sumber dasar yang merupakan bukti atau saksi utama dari kejadian yang lalu, dapat diperoleh dari hasil observasi, surat 
Fahmi, et al/Jurnal Ekonomi Syariah Teori dan Terapan Vol. 4 No. 12 Desember 2017: 968-976; PELAKSANAAN FUNGSI MANAJEMEN (PLANNING, ORGANIZING, ACTUALLING, CONTROLLING) PADA MANAJEMEN MASJID AL-AKBAR SURABAYA

keterangan oleh saksi mata, dan wawancara. (Nazir, 2003:49)

Data sekunder adalah catatan tentang adanya suatu peristiwa, ataupun catatan yang jaraknya telah jauh dari sumber orisinil, dapat diperoleh melalui dari suatu obyek penelitian berupa arsip, laporan-laporan, studi kepustakaan yang berkaitan dengan permasalahan, dan dokumen yang relevan (Nazir, 2003:50).

\section{Teknik Keabsahan Data}

Penelitian ini menggunakan teknik triangulasi dalam pemeriksaan keabsahan data. Teknik triangulasi merupakan teknik pemeriksaan yang memanfaatkan sesuatu yang lain (Yin, 2014: 119). Terdapat tiga teknik triangulasi yakni triangulasi sumber, triangulasi teknik dan triangulasi waktu. Triangulasi yang digunakan dalam penelitian ini adalah triangulasi sumber yakni dengan cara membandingkan dan mengecek informasi yang diperoleh.

\section{Teknik Analisis}

Dalam penelitian ini setelah dilakukan pengumpulan data, maka data tersebut dianalisis untuk mendapatkan kesimpulan. Teknik analisis data yang digunakan dalam penelitian ini adalah pembuatan eksplanasi. Menurut Yin (2014) pembuatan eksplanasi untuk menjelaskan fenomena atau menetapkan serangkaian timbal balik mengenai fenomena tersebut. Dalam studi kasus yang menggunakan metode deskriptif, pembuatan eksplanasi pada umumnya selama ini menggunakan eksplanasi dalam bentuk naratif.

\section{HASIL DAN PEMBAHASAN}

Masjid Al-Akbar Surabaya, atau yang lebih dikenal oleh warga Surabaya sebagai Masjid Agung, terletak di kawasan Surabaya Selatan. Lokasinya yang berada di tepi jalan tol Surabaya-Malang menjadikan Masjid Al-Akbar sebagai landmark kota Surabaya dan sangat mudah menjangkaunya. Begitu mudahnya Masjid Al-Akbar untuk dijangkau membuat wisatawan tertarik untuk mengunjungi dan menjadikan tempat ini sebagai wisata religi.

Masjid menurut fungsinya merupakan sarana untuk membangun spritualitas umat. Jadi jika spiritnya bisa dibangun dengan baik makan itu akan menjadi pendorong untuk menggerakkan umat untuk menyejahterakan masjid tersebut. Dengan melihat fungsi tersbut, maka di sini diperlukan manajemen yang baik dalam pengelolaannya dan pengurus yang bekerja secara professional. Masjid Al-Akbar diharapkan menjadi model percontohan untuk masjid-masjid lain karena posisinya sebagai salah satu masjid nasional.

Fungsi manajemen menurut Daft (2002:27), dibagi menjadi empat bagian:

1. Perencanaan

2. Pengorganisasian

3. Pelaksanaan

4. Pengendalian

Perencanaan di Masjid Al-Akbar selalu berawal dari bawah atau dimulai dari 
Fahmi, et al/Jurnal Ekonomi Syariah Teori dan Terapan Vol. 4 No. 12 Desember 2017: 968-976; PELAKSANAAN FUNGSI MANAJEMEN (PLANNING, ORGANIZING, ACTUALLING, CONTROLLING) PADA MANAJEMEN MASJID AL-AKBAR SURABAYA

unit-unit yang ada di bawah setiap bidang dan direktorat. Karena mereka yang lebih mengerti masalah lapangan dan jalannya unit tersebut. Unit-unit yang telah melakukan perencanaan tersebut mebawa hasil rapat unit ke rapat rutin pusat untuk mendapatkan persetujuan dari direktur utama masjid Al-Akbar. Oleh karena itu, data itu dari bawah, tetapi dalam pembuatan perencanaan tersebut sudah terdapat batasan rancangan.

Masjid Al-Akbar melaksanakan sistem pengorganisasian secara berkelompok dalam setiap bidang dan dalam bidang tersebut memiliki berbagai unit yang menyentuh ke semua urusan yang ada di tubuh masjid tersebut. Pengelompokan ini didasarkan karena tidak ada pengurus yang mampu untuk menguasai atau mengatasi segala bidang atau unit yang ada. Selain itu, jika dipegang oleh orang yang ahli di bidangnya maka akan terjadi efektivitas dan efisiensi dalam bekerja sehingga pekerjan akan dapat hasil yang optimal.

Aset menurut Kiseo (2007:11-12) adalah sumber penghasilan atas usahanya sendiri, dimana karakteristik umum yang dimilikinya yaitu memberikan jasa atau manfaat di masa yang akan datang, sedangkan Hanafi (2003:24) menjelaskan bahwa aset adalah sumber daya yang dikuasai oleh perusahaan sebagai akibat dari peristiwa masa lalu dan darinya manfaat ekonomi di masa depan diharapkan akan diraih oleh perusahaan.

Masjid Al-Akbar memiliki aset yang dikelola sendiri maupun dengan proses kerjasma dengan pihak luar. Aset yang dimiliki berupa gedung dan ruanganruangan yang disewakan, begitu juga dengan lahan di sekitar Masjid Al-Akbar Surabaya. Selain berupa tanah dan bangunan, aset lain yang dimiliki adalah unit-unit usaha yang ada di lingkungan Masjid Al-Akbar Surabaya. Ditambah pula siswa-siswi yang bersekolah di sekolah yang dirintis oleh Masjid Al-Akbar Surabaya. Asetaset yang dimiliki dikelola dengan baik dan telah diatur oleh aturan yang telah ditetapkan.

Kemandirian keuangan Masjid adalah kemampuan Masjid dalam menutupi biayabiaya seluruh kegiatan yang dilakukan untuk mencapai visi dan misi masjid. Masjid yang mandiri adalah Masjid yang mampu menjalankan roda kehidupan Masjid tersebut tanpa bergantung kepada pihak lain. Masjid yang mandiri mampu mempertahankan keberadaan walaupun tanpa menerima dana bantuan dari pihak lain.

Masjid Al-Akbar saat ini tidak hanya sebatas merawat aset yang dimiliki tetapi juga sudah mengembangkan apa yang ada. Mereka juga bekerja sesuai dengan nilai-nilai yang dijadikan pedoman oleh para pengelola masjid, salah satunya adalah istiqamah yaitu "konsisten dalam 
Fahmi, et al/Jurnal Ekonomi Syariah Teori dan Terapan Vol. 4 No. 12 Desember 2017: 968-976; PELAKSANAAN FUNGSI MANAJEMEN (PLANNING, ORGANIZING, ACTUALLING, CONTROLLING) PADA MANAJEMEN MASJID AL-AKBAR SURABAYA

mengemban visi dan misi yang telah ada dan terus mengadakan inovasi."

$\begin{array}{ccc}\text { Masjid } & \text { Al-Akbar sudah mampu } \\ \text { membiayai } & \text { semua keperluan yang } \\ \text { dibutuhkan dengan mengandalkan }\end{array}$
pendapatan yang diterima dari mengelola aset. Gaji para pengelola tidak diambil dari infaq masjid, tetapi dari pendapatan yang masuk dari penyewaan gedung dan unit usaha lainnya. Itu disebabkan Masjid AlAkbar benar-benar memaksimalkan aset yang ada, hampir semua bagian di lingkungan Masjid dapat menghasilkan pendapatan.

\section{SIMPULAN}

Berdasarkan hasil dari pembahasan dapat disimpulkan bahwa Masjid Al-Akbar Surabaya mempunyai tiga direktorat utama yang menaungi segala aspek yang ada di masjid tersebut. Tiga direktorat itu adalah Idarah,yang mengawasi masalah kevangan dan aset, Imarah,yang mengawasi peribadatan dan peringatan hari besar islam (PHBI), dan Tarbiyah, yang mengawasi masalah pendidikan. Masing direktur bertanggung jawab pada satu direktur utama Masjid Al-Akbar.

Masjid Al-Akbar Surabaya sudah mampu membiayai kebutuhan operasional dengan menggunakan pendapatan yang diterima dari mengelola aset yang ada. Aset yang ada pun sudah dikelola dengan baik karena dikelola oleh tenaga-tenaga yang telah diseleksi dengan baik. Tenaga kerja bisa melaksanaan pengelolaan aset dengan baik karena mereka diberi gaji yang layak. Jadi, pengelolaan aset yang optimal bisa menutupi semua kebutuhan baik itu kebutuhan operasional atau kebutuhan pengembangan fasilitas.

Pengelolaan aset yang ada sudah baik karena hampir seluruh tempat di masjid tersebut bisa menghasilkan pendapatan untuk masjid. Masjid Al-Akbar juga sudah berinovasi dengan menggandeng perusahaan lain untuk merawat dan mengoperasikan aset tersebut. Seperti contoh Secure Park yang mengelola parkir di Masjid Al-Akbar. Ini membuktikan bahwa Masjid Al-Akbar ingin selalu berinovasi dan berkembang untuk mengikuti perkembangan zaman.

Masjid Al-Akbar Surabaya juga sudah mempunyai kemandirian keuangan yang bagus. Kemandirian keuangan ini dibuktikan dengan perbandingan antara pendapatan yang didapat dari pengelolaan aset lebih besar dari pada dana dari luar yang meliputi infaq dan shadaqah dari para donatur. Masjid juga tidak menerima bantuan rutin dari pemerintah, bantuan dari pemerintah hanya turun jika masjid melakukan permohonan pengadaan barang seperti escalator dan karpet.

\section{DAFTAR PUSTAKA}

Al-Faruq, Asadullah. 2010. Panduan Lengkap Mengelola dan Memakmurkan Masjid. Solo: Pustaka Arafah 
Fahmi, et al/Jurnal Ekonomi Syariah Teori dan Terapan Vol. 4 No. 12 Desember 2017: 968-976; PELAKSANAAN FUNGSI MANAJEMEN (PLANNING, ORGANIZING, ACTUALLING, CONTROLLING) PADA MANAJEMEN MASJID AL-AKBAR SURABAYA

Baridwan, Zaki. 2004. Intermediet Accounting Edisi 8. Yogyakarta: BPFE-UGM

Daft, Richard L. 2002. Manajemen Edisi Kelima Jilid I. Jakarta: Erlangga

Djarwanto.2001. Pokok-Pokok Analisa Laporan Kevangan. Yogyakarta: BPPE UGM

Fadillah, Nurul. 2011 . Nilai Keuanggulan Bidang Pelayanan Masjid Nasional Al-Akbar Surabaya. Skripsi tidak diterbitkan. Surabaya Fakultas EKonomi dan Bisnis Universitas Airlangga

Gazalba, Sidi. 1975. Masjid Pusat Ibadat dan Kebudayaan Islam. Jakarta: Pustaka Antara

Halim, Abdul. 2007. Akuntansi Sektor Publik: Akuntansi Keuangan Daerah. Salemba Empat: Jakarta.

Hasting, Nicholas A. John. 2010. Physical Asset Management. Austria: Springer.

Kemenag Surabaya. 2013. Jumlah Masjid di Surabaya. Surabaya: Pusat Data Kemenag.

Kiseo, Weygandt. 2007. Intermediete Accounting, $12^{\text {th }} \quad$ Edition. Jakarta:Erlangga.
Nazir, Moh.2003. Metode Penilitian. Salemba Empat. Jakarta

Rivai, Veithzal \& Andi Buchari.2009. Islamic Economic : Ekonomi Syariah Bukan Opsi Tetapi Solusi. Jakarta: Bumi Aksara

Thaha, As'Ad.2006. Solusi Syar'i Problematika Pengelolaan Masjid.Kab.Gresik: Pimpinan Daerah Dewan Masjid Indonesia.

Shihab, M. Quraish, 2009, Tafsir AlMisbah, Pesan, Kesan, dan Keserasian AIQur'an, Vol.1, Lentera Hati: Jakarta

Siregar, Doli D. 2004. Manajemen Aset. Jakarta: Raja Gramedia Pustaka.

Sugiama, A Gima. 2013. Manajemen

Aset Pariwisata: Pelayanan

Berkualitas

agar Wisatawan Puas dan Loyal. Bandung: Guardaya Intimerta.

Sugiyono. 2010. Metode Penelitiaan Kuantitatif, Kualitatif, dan RND. Bandung:Alfabeta.

Yin. Robert K. 2014. Studi Kasus Desain dan Metode. Rajawali Pers: Jakarta. 